\title{
The effect of postoperative pain on postoperative blood loss after sequential bilateral total knee arthroplasty
}

\author{
So Yeon Kim", Yong Jun $\mathrm{An}^{1}$, Soo Hwan Kim³ ${ }^{3}$ Ha-Kyoung Kim ${ }^{1}$, Jeong Soo Park ${ }^{1}$, and Yang-Sik Shin ${ }^{1,2}$ \\ ${ }^{1}$ Department of Anesthesiology and Pain Medicine, ${ }^{2}$ Anesthesia and Pain Research Institute, Yonsei University College of Medicine, \\ ${ }^{3}$ Department of Anesthesiology and Pain Medicine, Kangnam Sacred Heart Hospital, Hallym University College of Medicine, Seoul, \\ Korea
}

Background: Bilateral total knee arthroplasty is generally accompanied by a significant amount of blood loss. We investigated the relationship between the intensity of pain and the amount of blood loss in the early postoperative period after bilateral total knee arthroplasty.

Methods: A prospective study was conducted on 91 patients who underwent elective sequential bilateral total knee arthroplasty for osteoarthritis. All patients received combined spinal and epidural anesthesia. Patients were divided into three groups based on their scores on the verbal numerical rating scale (VNRS) for pain at 6 hours postoperatively. The VNRS was classified as follows; mild pain ( $\mathrm{n}=34$, VNRS score $0-4$ ), moderate pain $(\mathrm{n}=24$, VNRS score 5-6), and severe pain ( $\mathrm{n}=33$, VNRS score $7-10)$. We compared the mean arterial pressures and the amount of blood loss during the first 24 postoperative hours in the three groups. Factors influencing postoperative blood loss were analyzed.

Results: Postoperative mean arterial pressures and blood loss were not different among the groups. Of the factors examined, the amount of postoperative blood loss was only dependent on the amount of intraoperative blood loss ( $\mathrm{P}$ $=0.001$ ).

Conclusions: Early postoperative pain has no effect on postoperative blood pressure and the amount of blood loss after bilateral total knee arthroplasty. For postoperative blood loss, intraoperative blood loss is the main determinant. (Korean J Anesthesiol 2011; 60: 98-102)

Key Words: Arthroplasty, Blood loss, Knee, Postoperative pain.

Received: June 17, 2010. Revised: 1st, July 15, 2010; 2nd, July 23, 2010. Accepted: July 27, 2010.

Corresponding author: Yang-Sik Shin, M.D., Department of Anesthesiology and Pain Medicine, Anesthesia and Pain Research Institute, Yonsei University College of Medicine, 250, Seongsan-no, Seodaemun-gu, Seoul 120-752, Korea. Tel: 82-2-2228-2412, Fax: 82-2-2227-7897, E-mail: ysshin@yuhs.ac

(c) This is an open-access article distributed under the terms of the Creative Commons Attribution Non-Commercial License (http:// creativecommons.org/licenses/by-nc/3.0/), which permits unrestricted non-commercial use, distribution, and reproduction in any medium, provided the original work is properly cited. 


\section{Introduction}

Management of bleeding is a primary concern during the perioperative period. Total knee arthroplasty (TKA) is accompanied by significant blood loss that often requires blood transfusions $[1,2]$. In particular, bilateral TKA results in increased blood loss $[3,4]$. During TKA, a tourniquet is used to reduce unnecessary bleeding and secure a clear operative field. Therefore, most bleeding occurs after tourniquet release rather than during the operation.

Hypotensive epidural anesthesia has been suggested as a technique for reducing perioperative blood loss and the need for blood transfusion in TKA and total hip arthroplasty $[5,6]$. Another study revealed that high blood pressure due to postoperative pain may influence postoperative blood loss in TKA [7]. In addition, there was a significance correlation between postoperative blood loss and morphine consumption [7]. Considering that pain scores and opioid consumption are higher in patients after bilateral TKA than unilateral TKA [8], the effect of postoperative pain on postoperative blood loss may be clearer in bilateral TKA. To date, no comprehensive data is available on the relationship between postoperative pain and blood loss in patients with patient-controlled epidural analgesia after sequential bilateral TKA.

The aim of this study was to investigate the relationship between early postoperative pain intensity and postoperative blood loss in patients after bilateral TKA.

\section{Materials and Methods}

This study was approved by the Hospital Ethics Committee and written informed consent was obtained from all patients before surgery. From February 2007 to November 2007, a prospective study was conducted on 91 patients who underwent elective sequential bilateral TKA for osteoarthritis. Patients were excluded from the study if any of the following criteria were present: current infectious disease, history of neurological disease, preoperative hemoglobin $<10 \mathrm{~g} / \mathrm{dl}$, coagulopathy, American Society of Anesthesiologists (ASA) class IV, past or current alcohol or narcotic abuse, and hypersensitivity to opioid or local anesthetics.

None of the patients were pre-medicated. Lactated Ringer's solution was injected intravenously via a 20-gauge IV catheter and an external jugular vein was accessed for blood transfusion with an 18-gauge IV catheter. Patients received approximately $300 \mathrm{ml}$ of lactated Ringer's solution before spinal anesthesia. All patients received combined spinal-epidural (CSE) anesthesia administered by anesthesiologists familiar with the technique in regional anesthesia. CSE was performed with a CSE kit (Espocan $^{\circledR}$, B. Braun, Melsungen, Germany) at L2-3 or L3-4 with the patient in the left lateral decubitus position. After local infiltration with $2 \mathrm{ml}$ of $1 \%$ lidocaine, an 18-gauge epidural needle was placed first in the epidural space using the loss of resistance technique with air. A 27-gauge spinal needle was then introduced through the epidural needle into the subarachnoid space, and free flow of cerebrospinal fluid (CSF) was observed. The spinal anesthetic solution was prepared as follows: $1 \mathrm{ml}$ of $1 \%$ tetracaine was taken from a vial of powdered tetracaine (Pantocainsterile inj. ${ }^{\circledR}$, Daihan Pharm., Seoul, Korea) dissolved in $2 \mathrm{ml}$ of $0.9 \% \mathrm{NaCl}$. This was mixed with $1 \mathrm{ml}$ of the patient's CSF and $0.1 \mathrm{ml}$ of $0.1 \%$ epinephrine to make $2 \mathrm{ml}$ of $0.5 \%$ isobaric tetracaine. Then, $2 \mathrm{ml}$ of $0.5 \%$ isobaric tetracaine was injected at a rate of $0.1 \mathrm{ml} / \mathrm{sec}$ with upward orientation of the spinal needle bevel. The epidural catheter was inserted $4 \mathrm{~cm}$ upward from the spinal puncture level. If systolic arterial pressure decreased below $90 \mathrm{mmHg}$ or to a level less than $75 \%$ from the baseline value, $4-8 \mathrm{mg}$ of IV ephedrine was administered. The patients were kept in a neutral supine position until the sensory block peaked. Surgery was initiated when the level of sensory block was at the T10 dermatome, which was confirmed by a pin-prick test with a 22 $\mathrm{G}$ hypodermic needle on each side of the midthoracic line. The epidural infusion pump used $225 \mathrm{mg}$ of $0.225 \%$ ropivacaine, $1.5 \mu \mathrm{g} / \mathrm{kg}$ of sufentanil, $0.6 \mathrm{mg}$ of naloxone, and $0.9 \%$ normal saline in a $100 \mathrm{ml}$ solution. The patient-controlled analgesia device (Accufuser Plus ${ }^{\circledR}$, P2015M, Woo Young Medical, Seoul, Korea) was designed to deliver a dose of $2 \mathrm{ml} /$ hour, with an "on-demand" bolus of $0.5 \mathrm{ml}$ every 15 minutes, and was withdrawn at 48 hours. The same surgeon performed all surgical procedures to maintain a uniform application of the surgical stimulus. The sequential arthroplasty was performed by one team under a single episode of anesthesia. A midline incision and parapatellar arthrotomy was made using standard surgical techniques. Following instrumented bone resection, the total knee components were fixed. The tourniquet and drain clamp were released after the skin wound was sutured. A SureTrans ${ }^{\circledR}$ autotransfusion system (Davol Inc, Cranston, RI, USA) was inserted near the medial aspect of the joint space and stayed in place for 24 hours after the surgery. Thromboembolic prophylaxis was ensured by enoxaparin $40 \mathrm{mg}$ administered subcutaneously once a day beginning on postoperative day 1 .

Preoperative data including age, sex, height, weight, hemoglobin level, and the presence of pre-existing medical conditions such as diabetes mellitus and hypertension, were recorded. Mean arterial pressures were checked preoperatively, intraoperatively, and at 6, 12, and 24 hours postoperatively. To exclude the effect of residual spinal anesthesia, pain was evaluated at 6,12 , and 24 hours postoperatively using an 11-point verbal numerical rating scale (VNRS). Patients were instructed preoperatively to express their pain on the $0-10$ 
Table 1. Patient Characteristics

\begin{tabular}{|c|c|c|c|c|}
\hline & \multicolumn{3}{|c|}{ Intensity of pain } & \multirow[b]{2}{*}{$\mathrm{P}$ value } \\
\hline & $\begin{array}{c}\text { Mild } \\
(n=34)\end{array}$ & $\begin{array}{c}\text { Moderate } \\
(\mathrm{n}=24)\end{array}$ & $\begin{array}{l}\text { Severe } \\
(n=33)\end{array}$ & \\
\hline Age (yr) & $71 \pm 5$ & $69 \pm 5$ & $69 \pm 7$ & 0.305 \\
\hline $\operatorname{Sex}(M / F)$ & $1 / 33$ & $1 / 23$ & $1 / 32$ & 0.962 \\
\hline Height $(\mathrm{cm})$ & $152 \pm 7$ & $154 \pm 5$ & $152 \pm 7$ & 0.384 \\
\hline Weight (kg) & $62 \pm 9$ & $65 \pm 9$ & $63 \pm 10$ & 0.540 \\
\hline Hypertension & 20 & 19 & 20 & 0.228 \\
\hline Diabetes mellitus & 7 & 4 & 9 & 0.615 \\
\hline Preoperative hemoglobin (g/dl) & $12.7 \pm 1.2$ & $13.0 \pm 1.1$ & $13.0 \pm 1.2$ & 0.543 \\
\hline Preoperative MAP (mmHg) & $93 \pm 11$ & $91 \pm 10$ & $94 \pm 11$ & 0.696 \\
\hline Intraoperative MAP (mmHg) & $94 \pm 8$ & $93 \pm 10$ & $91 \pm 10$ & 0.499 \\
\hline Intraoperative blood loss (ml) & $200(150-300)$ & $200(200-350)$ & $200(180-320)$ & 0.401 \\
\hline Duration of operation (min) & $125(120-138)$ & $120(115-139)$ & $130(125-140)$ & 0.110 \\
\hline
\end{tabular}

Values are mean \pm SD, median (interquartile range) or number of patients. MAP: mean arterial pressure.

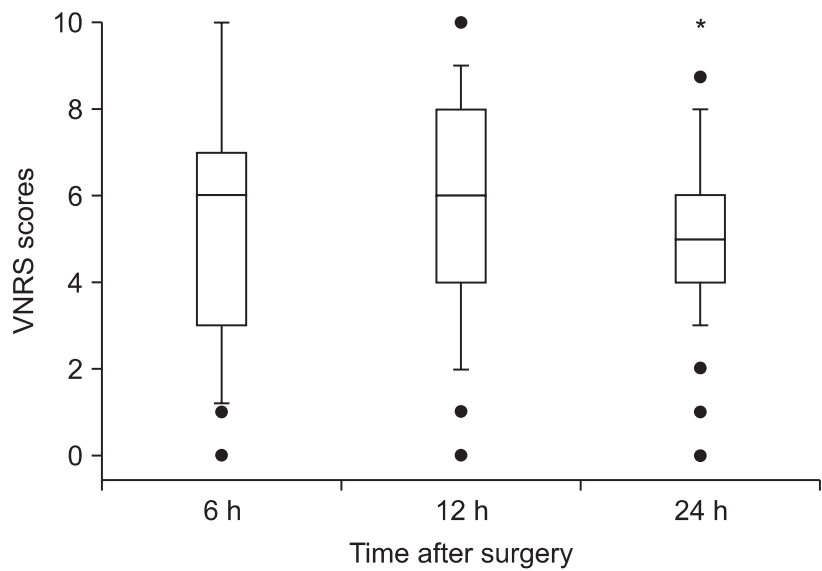

Fig. 1. Verbal numerical rating scale (VNRS) scores for pain at 6, 24, and 48 hours after surgery for all patients. Box plot with median (solid line), interquartile ranges (box) and values within 1.5 interquartile ranges from each side of the box (whiskers). Outliers are indicated by solid circles. Bonferroni correction: $* \mathrm{P}=0.003$ compared with 12 hours.

VNRS, where a score of 0 represents no pain at all and a score of 10 represents the worst pain imaginable. The amount of intraoperative blood loss was obtained by weighing sponges and measuring blood recovered in suction canisters. Postoperative blood loss was obtained by measuring the volume of blood drained in SureTrans ${ }^{\circledR}$ at 6, 12, and 24 hours postoperatively. Since approximately $70 \%$ of the total drained blood is usually collected within 6 hours postoperatively [9], we divided the groups according to the VNRS at 6 hours postoperatively to determine the effect of postoperative pain on postoperative blood loss. The patients were divided into three groups, which were mild pain $(\mathrm{n}=34$, VNRS score $0-4)$, moderate pain $(\mathrm{n}=24$, VNRS score 5-6), and severe pain ( $\mathrm{n}=33$, VNRS score $7-10)$ [10].

Statistical analysis was performed using SPSS 13.0 (SPSS Inc., Chicago, IL, USA) or SAS software 9.2 (SAS Inc., Cary, NC, USA). The normality of distribution was assessed with a q-q
Table 2. Mean Arterial Pressure during the Postoperative 24 Hours

\begin{tabular}{lcccc}
\hline & \multicolumn{3}{c}{ Intensity of pain } & \\
\cline { 2 - 4 } & $\begin{array}{c}\text { Mild } \\
(\mathrm{n}=34)\end{array}$ & $\begin{array}{c}\text { Moderate } \\
(\mathrm{n}=24)\end{array}$ & $\begin{array}{c}\text { Severe } \\
(\mathrm{n}=33)\end{array}$ & P value \\
\hline 6 hour & $88 \pm 9$ & $89 \pm 12$ & $90 \pm 12$ & 0.835 \\
12 hour & $96 \pm 11$ & $96 \pm 14$ & $95 \pm 14$ & 0.961 \\
24 hour & $99 \pm 11$ & $95 \pm 10$ & $95 \pm 12$ & 0.228
\end{tabular}

Values are mean $\pm \mathrm{SD}(\mathrm{mmHg})$

plot and the Shapiro-Wilk test. All data were expressed as mean $\pm \mathrm{SD}$, median (interquartile range), or the number of patients according to the distribution of normality. Data was compared among the groups using one-way ANOVA, the KruskalWallis test or chi-square test. If the Kruskal-Wallis test proved significant, a Mann-Whitney U test with Bonferroni correction was used to evaluate differences among the groups. Factors influencing postoperative blood loss were analyzed using linear mixed models. A P value of less than 0.05 was considered statistically significant.

\section{Results}

CSE anesthesia was successfully accomplished in all patients. Patient characteristics were similar among the three groups (Table 1). VNRS scores for pain of all patients during the postoperative period are shown in Fig. 1. The median VNRS score was lower at 24 hours than at 12 hours postoperatively (5 [IQR 4-6] versus 6 [IQR 4-8], respectively; Bonferronicorrected $\mathrm{P}=0.003$ ).

Mean arterial pressures at 6,12 , and 24 hours postoperatively were not different among the three groups (Table 2). Amount of blood loss at 6,12 , and 24 hours postoperatively and total blood loss also did not significantly differ among the three groups (Fig. 2). The number of units of packed red blood cells 


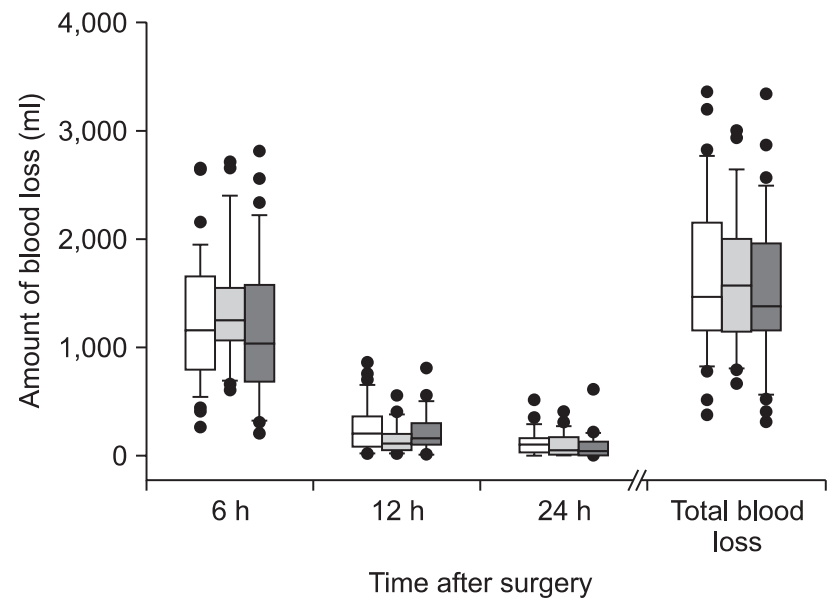

Fig. 2. The amount of postoperative blood loss in the 24 hours after surgery. Box plot with median (solid line), interquartile ranges (box) and values within 1.5 interquartile ranges from each side of the box (whiskers). Outliers are indicated by solid circles. Total blood loss is the sum of the amount of blood loss during 24 hours postoperatively. There were no significant differences among the groups.

transfused was the same for all three groups [median 0 unit (range 0-2)]. After linear mixed model analysis, the amount of intraoperative blood loss was a statistically significant factor for the amount of postoperative blood loss $(\mathrm{P}=0.001)$ (Table 3$)$.

\section{Discussion}

TKA is a procedure that is being performed at an increasing rate as the result of an increasing mean age of the population. Although the majority of patients with arthritis of the knee undergo unilateral TKA, patients often present with symptomatic arthritis of both knees. Even though concomitant bilateral TKA is associated with a higher rate of complications $[3,11,12]$, there are many advantages to performing sequential bilateral arthroplasty under one episode of anesthesia. In particular, the preference of patients for a concomitant bilateral TKA and their satisfaction following the procedure are high due to a shorter hospitalization time, a faster return to function in their daily lives, and a reduction of medical costs compared with staged TKA $[4,13,14]$.

This study shows that postoperative pain intensity does not affect postoperative blood loss after bilateral TKA. This result differs from that of a previous study which demonstrated that elevated postoperative pain significantly correlated with increased postoperative blood loss after TKA, and the mean arterial pressure at 6 hours after surgery was also a factor influencing the number of transfused units of blood [7]. However, in our study, postoperative VNRS scores and mean arterial pressures were not a factor for postoperative blood loss (Table 3). Even though the amounts of blood lost during the
Table 3. Factors Influencing Postoperative Blood Loss: Linear Mixed Model

\begin{tabular}{lcrr}
\hline \multicolumn{1}{c}{ Variable } & $\begin{array}{c}\text { Estimate } \\
\text { (Standard error) }\end{array}$ & t value & P value \\
\hline Age & $5.29(3.16)$ & 1.67 & 0.095 \\
Sex & $-179.27(108.40)$ & -1.65 & 0.099 \\
Body mass index & $4.75(5.43)$ & 0.88 & 0.382 \\
Hypertension & $40.30(36.86)$ & 1.09 & 0.275 \\
Diabetes mellitus & $-72.41(44.18)$ & -1.64 & 0.102 \\
Preoperative hemoglobin & $-27.39(16.29)$ & -1.68 & 0.094 \\
Intraoperative blood loss & $0.50(0.14)$ & 3.55 & 0.001 \\
Postoperative VNRS score & $2.24(6.66)$ & 0.34 & 0.736 \\
Postoperative MAP & $1.16(1.35)$ & 0.86 & 0.390 \\
Duration of operation & $-0.20(1.06)$ & -0.19 & 0.852 \\
\hline VNRS: verbal numerical rating scale, MAP: mean arterial pressure.
\end{tabular}

operation were not high (median $200 \mathrm{ml}$ [IQR 150-300]) due to the use of a tourniquet, only the amount of intraoperative blood loss was a factor influencing postoperative blood loss. Therefore, in contrast to the previous study [7], postoperative pain intensity did not act as a factor on postoperative blood loss. The possible reason for different results between this study and the previous study [7] may be due to differences in the type of surgery (unilateral versus bilateral) and the methods of postoperative analgesia (intravenous (IV) patient-controlled analgesia (PCA) versus IV PCA + continuous femoral nerve block versus IV PCA + continuous posterior lumbar plexus block versus epidural PCA). Therefore, according to the study design, the main factor for postoperative blood loss could be changed. In this study, instead of postoperative pain and mean arterial pressure, intraoperative surgical factors may be more important for postoperative blood loss. There are many factors influencing intraoperative blood loss, such as patient factors, surgeon factors, method of thromboprophylaxis, and the timing of tourniquet release [15-17]. We did not analyze the factors contributing to intraoperative blood loss, and this could be a limitation of this study. Considering that intraoperative blood loss is an important factor effecting postoperative blood loss, the use of antifibrinolytic or hemostatic agents proven to be effective in reducing postoperative blood loss [18-20] may be useful in case of heavy bleeding during the surgery.

Deliberate hypotension is a technique for reducing perioperative blood loss by significantly lowering arterial pressure, and has been studied extensively in major orthopedic procedures $[21,22]$. Hypotensive epidural anesthesia with a mean arterial pressure of 45 to $50 \mathrm{mmHg}$ has been shown to significantly reduce blood loss and the need for blood transfusion in TKA [6]. In the current study, intraoperative mean arterial pressure was maintained at about $90 \mathrm{mmHg}$ in the three groups. Therefore, the amount of intraoperative blood loss was similar among the three groups. In addition, despite the differences in pain intensity, postoperative mean arterial pressures were 
not different among the groups. If there was a difference in the mean arterial pressure postoperatively, there would likely be a difference in the amount of blood loss.

In this study, the average total blood loss was approximately $1,500 \mathrm{ml}$ during the first 24 hours after the operation. It has been reported that most blood loss occurs in the first few hours, with $50 \%$ occurring within the first 3 hours and $70 \%$ within the first 6 hours [6,9]. In accordance with previous results, about $79 \%$ of the total blood drainage was collected within 6 hours postoperatively and there were no differences among the groups. In addition to management of postoperative blood loss, postoperative pain is a major concern after TKA. After knee surgery, pain intensity is reportedly quite high [7,23-25]. Despite the use of epidural analgesia, the median VNRS score was 6 (IQR 3-7) at 6 hours, 6 (IQR $4-8$ ) at 12 hours, and 5 (IQR 4-6) at 24 hours after surgery in our study. Therefore, in addition to continuous epidural analgesia, multimodal approaches to pain control, such as peripheral nerve block and/or additional analgesics, may be needed in the early postoperative period [7,23,25].

In conclusion, the intensity of early postoperative pain is not a component for postoperative blood loss in sequential bilateral TKA. The amount of intraoperative blood loss correlates with the amount of postoperative blood loss.

\section{References}

1. Lotke PA, Faralli VJ, Orenstein EM, Ecker ML. Blood loss after total knee replacement. Effects of tourniquet release and continuous passive motion. J Bone Joint Surg Am 1991; 73: 1037-40.

2. Woolson ST, Wall WW. Autologous blood transfusion after total knee arthroplasty: a randomized, prospective study comparing predonated and postoperative salvage blood. J Arthroplasty 2003; 18: 243-9.

3. Lane GJ, Hozack WJ, Shah S, Rothman RH, Booth RE Jr, Eng K, et al. Simultaneous bilateral versus unilateral total knee arthroplasty. Outcomes analysis. Clin Orthop Relat Res 1997; (345): 106-12.

4. Dennis DA. Debate: bilateral simultaneous total knee arthroplasty. Clin Orthop Relat Res 2004; (428): 82-3.

5. Niemi TT, Pitkänen M, Syrjälä M, Rosenberg PH. Comparison of hypotensive epidural anaesthesia and spinal anaesthesia on blood loss and coagulation during and after total hip arthroplasty. Acta Anaesthesiol Scand 2000; 44: 457-64.

6. Juelsgaard P, Larsen UT, Sørensen JV, Madsen F, Søballe K. Hypotensive epidural anesthesia in total knee replacement without tourniquet: reduced blood loss and transfusion. Reg Anesth Pain Med 2001; 26: 105-10.

7. Guay J. Postoperative pain significantly influences postoperative blood loss in patients undergoing total knee replacement. Pain Med 2006; 7: 476-82.

8. Powell RS, Pulido P, Tuason MS, Colwell CW Jr, Ezzet KA. Bilateral vs unilateral total knee arthroplasty: a patient-based comparison of pain levels and recovery of ambulatory skills. J Arthroplasty 2006; 21: 642-9.
9. Han CD, Lee WY, Jahng JS. Comparison of the postoperative blood salvage systems in total knee arthroplasty. J Korean Knee Soc 1995; 7: 110-6.

10. Serlin RC, Mendoza TR, Nakamura Y, Edwards KR, Cleeland CS. When is cancer pain mild, moderate or severe? Grading pain severity by its interference with function. Pain 1995; 61: 277-84.

11. Lynch NM, Trousdale RT, Ilstrup DM. Complications after concomitant bilateral total knee arthroplasty in elderly patients. Mayo Clin Proc 1997; 72: 799-805.

12. Parvizi J, Sullivan TA, Trousdale RT, Lewallen DG. Thirty-day mortality after total knee arthroplasty. J Bone Joint Surg Am 2001; 83-A: 1157-61.

13. Vince KG. Bilateral total knee arthroplasty under one anesthesia: a safe protocol. Mayo Clin Proc 1997; 72: 883-5.

14. Leonard L, Williamson DM, Ivory JP, Jennison C. An evaluation of the safety and efficacy of simultaneous bilateral total knee arthroplasty. J Arthroplasty 2003; 18: 972-8.

15. Sculco TP. Blood management in orthopedic surgery. Am J Surg 1995; 170: 60S-3S.

16. Nelson CL. A guide to reduce allogeneic transfusions in elective orthopaedic surgery. Instr Course Lect 2005; 54: 35-41.

17. Bell TH, Berta D, Ralley F, Macdonald SJ, McCalden RW, Bourne $\mathrm{RB}$, et al. Factors affecting perioperative blood loss and transfusion rates in primary total joint arthroplasty: a prospective analysis of 1642 patients. Can J Surg 2009; 52: 295-301.

18. Florentino-Pineda I, Thompson GH, Poe-Kochert C, Huang RP, Haber LL, Blakemore LC. The effect of amicar on perioperative blood loss in idiopathic scoliosis: the results of a prospective, randomized double-blind study. Spine (Phila Pa 1976) 2004; 29: 233-8.

19. Mawatari M, Higo T, Tsutsumi Y, Shigematsu M, Hotokebuchi T. Effectiveness of autologous fibrin tissue adhesive in reducing postoperative blood loss during total hip arthroplasty: a prospective randomised study of 100 cases. J Orthop Surg (Hong Kong) 2006; 14: 117-21.

20. Yamasaki S, Masuhara K, Fuji T. Tranexamic acid reduces postoperative blood loss in cementless total hip arthroplasty. J Bone Joint Surg Am 2005; 87: 766-70.

21. Kim JM, Hong JH, Jang YH, Lee YC, Kwon SH. Comparison of blood loss according to different anesthetic technique for total hip replacement. Korean J Anesthesiol 2007; 53: 583-8.

22. Paul JE, Ling E, Lalonde C, Thabane L. Deliberate hypotension in orthopedic surgery reduces blood loss and transfusion requirements: a meta-analysis of randomized controlled trials. Can J Anaesth 2007; 54: 799-810.

23. Choi HG, Kim SG, Kwon SB, Kim JS, Kwon HU, Kang PS. The analgesic effect of postoperative combined epidural, soft tissue, and intraarticular injection of morphine and bupivacaine in patients undergoing total knee arthroplasty. Korean J Anesthesiol 2006; 50: 546-51.

24. Han CD, Lee DH, Yang IH. Intra-synovial ropivacaine and morphine for pain relief after total knee arthroplasty: a prospective, randomized, double blind study. Yonsei Med J 2007; 48: 295-300.

25. Singelyn FJ, Deyaert M, Joris D, Pendeville E, Gouverneur JM. Effects of intravenous patient-controlled analgesia with morphine, continuous epidural analgesia, and continuous three-in-one block on postoperative pain and knee rehabilitation after unilateral total knee arthroplasty. Anesth Analg 1998; 87: 88-92. 